\title{
Pharmacology of human experimental anxiety
}

F.G. Graeff ${ }^{1}$, A. Parente ${ }^{1}$, C.M. Del-Ben ${ }^{1}$ and F.S. Guimarães ${ }^{2}$
1Departamentos de Neurologia, Psiquiatria e Psicologia Médica, and ${ }^{2}$ Farmacologia, Faculdade de Medicina de Ribeirão Preto, Universidade de São Paulo, Ribeirão Preto, SP, Brasil

\section{Correspondence}

F.G. Graeff

Pós-Graduação em Saúde Mental

Departamento de Neurologia,

Psiquiatria e Psicologia Médica

FMRP, USP

Av. 9 de Julho, 980

14025-000 Ribeirão Preto, SP

Brasil

Fax: +55-16-635-0713

E-mail: fgraeff@keynet.com.br

Research supported by FAEPA, Hospital das Clínicas, FMRP-USP and FAPESP.

Received August 8, 2002 Accepted December 12, 2002 $\ldots \ldots \ldots \ldots \ldots \ldots \ldots$

\begin{abstract}
This review covers the effect of drugs affecting anxiety using four psychological procedures for inducing experimental anxiety applied to healthy volunteers and patients with anxiety disorders. The first is aversive conditioning of the skin conductance responses to tones. The second is simulated public speaking, which consists of speaking in front of a video camera, with anxiety being measured with psychometric scales. The third is the Stroop Color-Word test, in which words naming colors are painted in the same or in a different shade, the incongruence generating a cognitive conflict. The last test is a human version of a thoroughly studied animal model of anxiety, fear-potentiated startle, in which the eye-blink reflex to a loud noise is recorded. The evidence reviewed led to the conclusion that the aversive conditioning and potentiated startle tests are based on classical conditioning of anticipatory anxiety. Their sensitivity to benzodiazepine anxiolytics suggests that these models generate an emotional state related to generalized anxiety disorder. On the other hand, the increase in anxiety determined by simulated public speaking is resistant to benzodiazepines and sensitive to drugs affecting serotonergic neurotransmission. This pharmacological profile, together with epidemiological evidence indicating its widespread prevalence, suggests that the emotional state generated by public speaking represents a species-specific response that may be related to social phobia and panic disorder. Because of scant pharmacological data, the status of the Stroop ColorWord test remains uncertain. In spite of ethical and economic constraints, human experimental anxiety constitutes a valuable tool for the study of the pathophysiology of anxiety disorders.
\end{abstract}

\section{Introduction}

Animal models of psychopathology are widely used to develop new therapeutic agents as well as to investigate the mechanism of action of psychotherapeutic drugs and the pathophysiology of psychiatric disorders (1). Because of ethical and economical constraints, experiments that induce anxiety states
Key words

- Anxiety

- Experimental anxiety

- Humans

- Anxiolytic drugs

- Anxiety disorders

..... Anxiety disorders in human beings are less frequently used. Nevertheless, they may constitute a helpful bridge between animal models and clinical disorders.

Experimental anxiety in humans may be induced by either chemical (e.g., caffeine, pentylenetetrazol, yohimbine, $\mathrm{CO}_{2}$ inhalation) or psychological means. Only the latter will be reviewed here. In this class of tests, 
environmental stimuli or contexts are used to induce anxiety states in healthy volunteers. Yet, there are some difficulties in producing anxiety that is sensitive to anxiolytic drugs due to the low level of the anxiety produced that is allowed by ethical constraints. Also, the sedative and anxiolytic effects of drugs are often hard to distinguish (2). In spite of these shortcomings, some procedures have yielded valuable results, which are discussed below.

\section{Aversive conditioning to tones}

Classical conditioning plays a pivotal role in theories of anxiety (3). Through this process, originally neutral stimuli or contexts acquire the ability to elicit anxiety after pairing with painful or otherwise unpleasant stimuli.

Emotional states are accompanied by neurovegetative changes, among them an increase in activity of sweat glands of the hands, which are innervated by cholinergic fibers of the sympathetic nervous system. The secretion of such ionic solution increases electrical conductance of the skin, which can be easily measured by means of a galvanometer. As a consequence, recording of skin conductance responses (SCR) to stimuli is often used to measure conditioned anxiety in humans (4). Recently discussed evidence indicates that SCR is an index of activation of the "brain inhibition system", a theoretical construct that Gray and McNaughton (3) equate with anxiety (5).

Vila and Beech (6) developed a procedure of aversive conditioning measuring SCR elicited by a blue light before and after its pairing with a loud white noise. They demonstrated that the association increased the intensity of SCR, an indication of classical conditioning. Later on, Wang (7) used tones, instead of light, as the to-be-conditioned stimulus to study the effect of ethanol abstinence syndrome on aversive conditioning. A modified version of the last procedure has been used in several drug studies performed on healthy volunteers as well as on patients with anxiety disorders (8). This method is briefly described below.

The experimental session is conducted inside a temperature-controlled $\left(22 \pm 2^{\circ} \mathrm{C}\right)$ and sound-attenuated room. Skin conductance is measured using a constant voltage $(0.6 \mathrm{~V})$ device controlled by a personal computer. Two Ag-Ag Beckman electrodes are connected to the skin of the mid-phalanx of the second and third fingers of the left hand by means of two adhesive patches $1 \mathrm{~cm}$ in diameter. The contact is made through an electrically conductive gel.

A sound generator connected to an amplifier produces a white noise of $100-\mathrm{dB}$ loudness and 1-s duration, which elicits a startle response in the volunteer, but is neither unbearable nor harmful. A tone generator produces sounds of specified frequency that are clearly audible, but not unpleasant (80 dB, $1 \mathrm{~s})$. A personal computer controls the presentation of the sound stimuli to the experimental subject through bilateral headphones. The computer also records and later analyzes the SCR elicited by either the tone or the noise, or responses that occur spontaneously.

The following parameters are recorded: 1) magnitude of SCR, defined as a skin conductance fluctuation higher than 0.02 (or $0.05) \mu \mathrm{S}$ occurring within a 5 -s time window following sound presentation; 2) number of spontaneous fluctuations of similar characteristics, but that occur beyond the specified time window; 3) average skin conductance level, measured in the time intervals between stimuli.

After 10 min of adaptation to the laboratory, the experimental session starts with 10 presentations of the tone at pseudo-random intervals (average interval of $58 \mathrm{~s}$, ranging from 40 to $80 \mathrm{~s}$ ). In this habituation phase, the first tone elicits an SCR of high magnitude, but the intensity of the response steadily declines after each tone presentation. In the 
next, conditioning phase, the 11 th tone is immediately followed by the white noise the unconditioned stimulus, which elicits a major SCR. After a 1-min interval, the same tone - now a conditioned stimulus - is again presented 10 times, as before. Due to conditioning, the first conditioned stimulus elicits an SCR of magnitude comparable to that in response to the first tone. As in the first phase, the magnitude of the SCR decreases with recurrence of the tones (extinction), but at a rate far slower than in the habituation phase. Each subject participates in only one experimental session.

In a validation study, healthy volunteers were divided into two groups. The first one followed the above experimental protocol, whereas in the second group the 11th tone was omitted and the white noise was presented alone, so that no tone-noise pairing occurred. As illustrated in Figure 1, only a short-lasting increase in the magnitude of the SCR was observed in the third phase of the experiment, probably due to sensitization, which is a nonassociative process. In contrast, the sustained enhancement that occurs in the standard procedure is likely to be a consequence of the tone-noise association, that is, classical conditioning (8).

Table 1 summarizes reported pharmacological results (9-13).

It may be seen that the test is sensitive to anxiolytic agents such as diazepam, buspirone and ritanserin. Diazepam and buspirone facilitated both the habituation to the neutral tone and the extinction of the conditioned responses, while ritanserin affected extinction, but did not change habituation (Figure 2). Therefore, only ritanserin had a selective effect on aversive conditioning. The gender difference found with diazepam indicates that women are more sensitive to the anxiolytic effect of this drug. Probably, the difference was detected because the dose of diazepam (2 mg) was unusually small, $10 \mathrm{mg}$ being the standard dose. In the opposite direction, the anxiogenic agent methyl- chlorophenylpiperazine (mCPP) tended to facilitate conditioning. These results suggest that the aversive conditioning test can detect both anxiolytic and anxiogenic effects of drugs.

Most of the studies with the present model were aimed at testing the hypothesis that

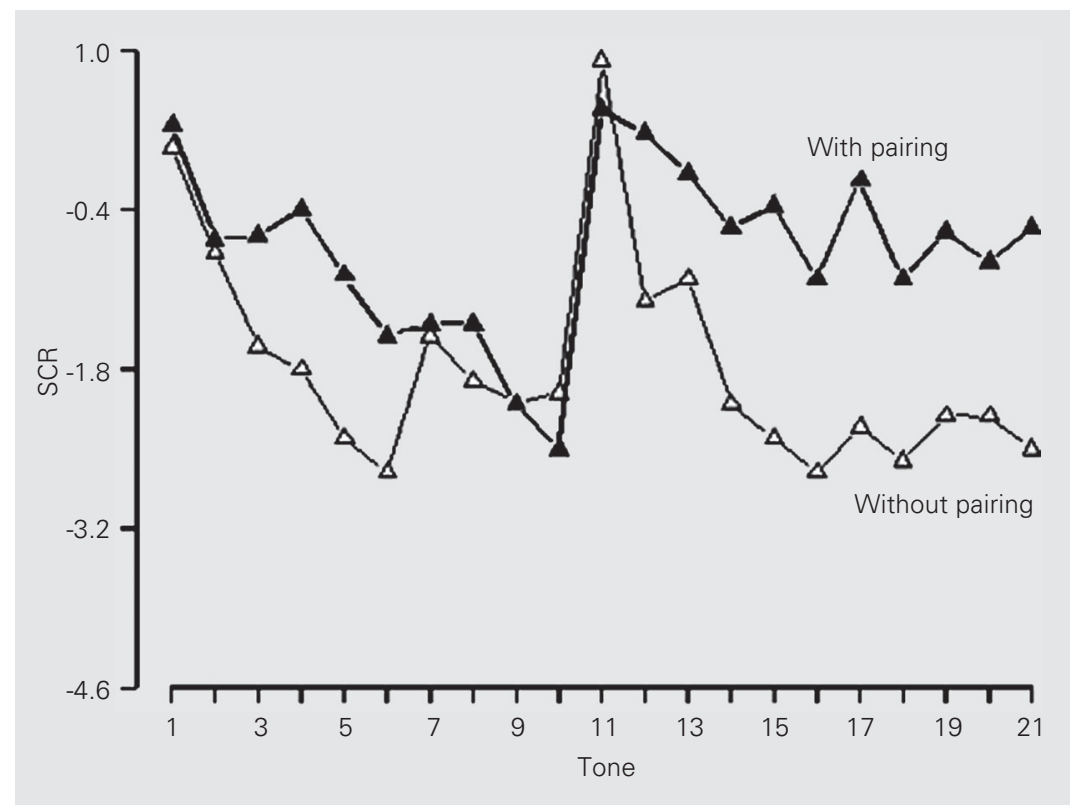

Figure 1. Skin conductance responses (SCR) of healthy volunteers undergoing aversive conditioning to tones. Points indicate the mean value of the natural log of SCR to each tone. In the group "With pairing" (filled triangles) the 11th tone was followed by noise (aversive unconditioned stimulus) presentation. Noise was absent in the group "Without pairing" (open triangles). $\mathrm{N}=10$. Modified from Ref. 8 .

Table 1. Effects of drugs on conditioned skin conductance responses.

\begin{tabular}{lcccc}
\hline Drug & $\begin{array}{c}\text { Dose } \\
(\mathrm{mg}, \text { po })\end{array}$ & \multicolumn{2}{c}{ Test phase } & Reference \\
\cline { 3 - 4 } & & Habituation & Extinction & \\
\hline Diazepam & 2 & $+^{\mathrm{a}}$ & $+^{\mathrm{a}}$ & Hellewell et al. (9) \\
Buspirone & 5 & + & + & Hellewell et al. (9) \\
Fluvoxamine & 25 & $+^{\mathrm{a}}$ & $+^{\mathrm{a}}$ & Hellewell et al. (9) \\
Ritanserin & 10 & 0 & + & Hensman et al. (10) \\
Nefazodone & 100 & 0 & 0 & Silva and Leite (11) \\
d-Fenfluramine & 200 & 0 & 0 & \\
mCPP & 15 & 0 & $-b$ & Hetem et al. (12) \\
m & 30 & 0 & 0 & \\
& 15 & 0 & $-b$ & Connel et al. (13) \\
\hline
\end{tabular}

$\mathrm{mCPP}=$ methyl-chlorophenylpiperazine. + , facilitation (anxiolytic); -, impairment (anxiogenic); 0 , no change. ${ }^{a}$ in women only; bnearly significant. 
serotonin (5-HT) affects conditioned and unconditioned anxiety in opposite directions (14). In this context, aversive conditioning to tones is viewed as a paradigm of conditioned anxiety, whereas simulated public speaking (see below) is supposed to represent unconditioned anxiety. According to the mentioned hypothesis, 5-HT is supposed to facilitate conditioned anxiety. Therefore, drugs that increase the action of 5-HT are expected to facilitate aversive conditioning. In turn, drugs that decrease the action of 5-HT should inhibit conditioning. From the results summarized in Table 1, it may be concluded that the anxiolytic effect of the $5-\mathrm{HT}_{2 \mathrm{~A} / 2 \mathrm{C}}$-receptor antagonist ritanserin fulfills the predictions of the hypothesis being tested. The tendency to an anxiogenic effect of the $5-\mathrm{HT}_{2 \mathrm{C}}$-receptor agonist $\mathrm{mCPP}$ and of the 5-HT-releasing agent d-fenfluramine is also consistent with these predictions.

However, the anxiolytic effects of both the $5-\mathrm{HT}_{1 \mathrm{~A}}$-receptor agonist buspirone and the selective 5-HT reuptake inhibitor fluvoxamine seem to be discordant results. Nevertheless, the authors of this study (9) have argued that reported neurochemical and elec-

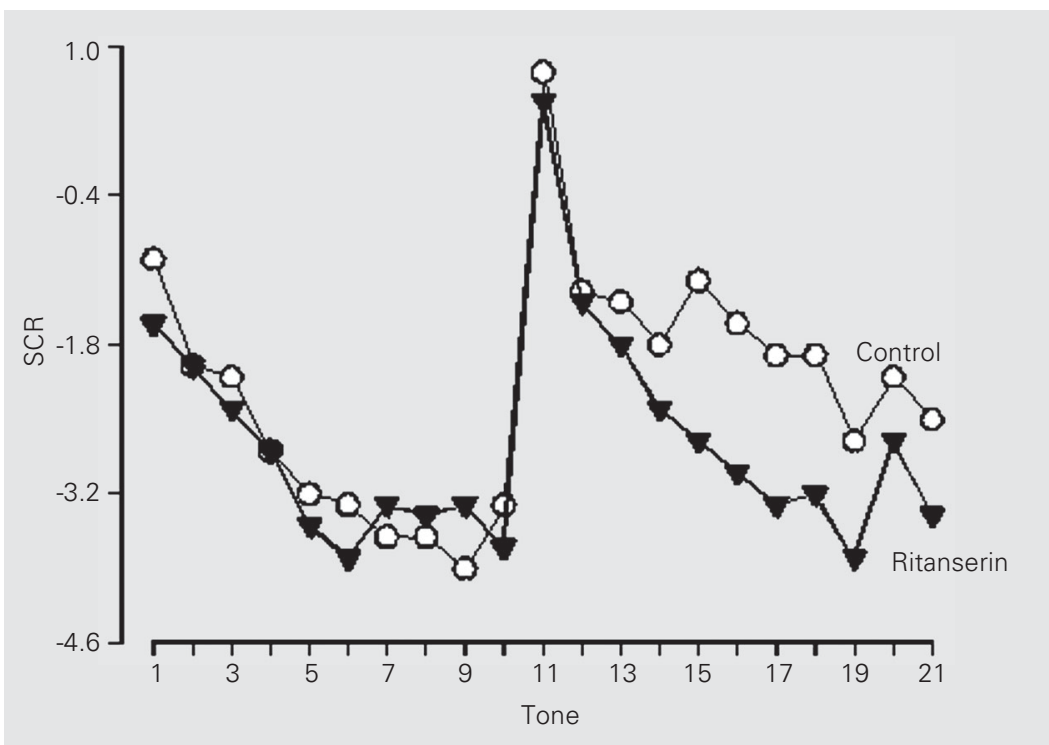

Figure 2. Anxiolytic effect of ritanserin ( $10 \mathrm{mg}$, po, triangles) measured in healthy volunteers undergoing the aversive conditioning test. Other specifications are given in the legend to Figure 1. SCR = skin conductance responses. Modified from Ref. 10. trophysiological results indicate that pre-synaptic $5-\mathrm{HT}_{1 \mathrm{~A}}$ receptors would be preferentially stimulated after acute administration of these drugs. These receptors are placed on the neuron bodies of serotonergic neurons of the brain stem raphe nuclei. Their stimulation reduces the firing rate of these neurons, thus decreasing $5-\mathrm{HT}$ release from $5-\mathrm{HT}$ terminals $(15,16)$. As a result, the ultimate functional consequence would be a reduction of 5-HT action on the postsynaptic neurons. Thus, buspirone and fluvoxamine would be expected to decrease anxiety, as observed.

The case of nefazodone is more complex, since the drug both blocks $5-\mathrm{HT}_{2 \mathrm{~A} / 2 \mathrm{C}}$ receptors and weakly inhibits 5-HT and noradrenaline reuptake (17). From the effects of ritanserin and fluvoxamine shown in Table 1, an anxiolytic effect of nefazodone would be expected. Yet, the drug did not significantly reduce aversive conditioning measured by the amplitude of the SCR to the tone. Nevertheless, the number of spontaneous fluctuations of skin conductance (not shown in Table 1) was significantly decreased following the highest dose $(200 \mathrm{mg})$ of the drug during both the habituation and the extinction phases of the test (18). Since the number of spontaneous fluctuations is regarded as an index of neurovegetative arousal (4) the effect of this drug may be interpreted to be anxiolytic.

Two studies have applied the aversive conditioning test to patients with anxiety disorders. The first one compared anxious patients to normal controls. Skin conductance level, variability (spontaneous fluctuations) and response amplitudes to tones were significantly greater in patients than controls. Habituation of skin conductance responses to the tone did not differ between groups. All subjects showed enhanced (conditioned) responses to the tones after the conditioning trial, but patients did not show greater conditioning than controls. The results indicate that anxious neurotic outpatients have greater sweat gland activity and 
reactivity than controls, but they fail to demonstrate differences in central mechanisms of habituation or conditioning (19). The second study used paired groups of normal subjects and panic patients. As in the preceding study, panic patients showed more spontaneous fluctuations of skin conductance than controls, but conditioning of skin conductance responses to the tone was similar in both groups (20). The last result indicates that panic patients process conditioned anxiety normally, in contrast to unconditioned anxiety (Figure 3).

\section{Simulated public speaking}

In 1965, Geer (21) demonstrated that fear of speaking in public is highly prevalent among students. On this basis, McNair and co-workers (22) developed and validated a model of clinical anxiety, named simulated public speaking (SPS), which consists of speaking in front of a video camera. Further studies have shown that fear of speaking in public is fairly constant across genders, races and ages (23). It is the most frequent social fear found in epidemiological studies, being intensified in social phobia (24-26). In addition, the SPS test has been shown to provoke anxiety in healthy volunteers irrespective of trait anxiety level, while another experimental model of anxiety, the Stroop Color-Word test (SCWT, see below), was anxiogenic only in persons with high trait anxiety (27). For these reasons, SPS is believed be a species-specific response.

Later, Guimarães and co-workers (28) modified the original procedure, and this version of the method has been used in several pharmacological studies. In the SPS test, the subject is requested to prepare a speech and then speak in front of a video camera, the performance being recorded on videotape. As in the aversive conditioning model, each subject participates in the SPS only once, but in addition to physiological measures, such as arterial blood pressure and heart rate, psychometric measures of subjective states are taken. These are Spielberger's (29) StateTrait Anxiety Inventory (STAI) and the Visual Analog Mood Scale (VAMS) developed by Norris (30). In this scale, the subject is told to mark a point that identifies his/her present subjective state on a $10-\mathrm{cm}$ strait line placed between two words that describe opposite mood states (e.g., calm - agitated). Factor analysis has grouped the items of the scale into four factors, namely anxiety, mental sedation, physical sedation and other feelings and attitudes $(30,31)$. Reported results have shown that VAMS is more sensitive than STAI-S in the detection of drug effects on anxiety $(28,31)$, provided initial instructions and supervision are given to limit the tendency to extreme choices by the subjects (32). In addition to these anxiety scales, a somatic symptom scale is also used to measure somatic symptoms that interfere with anxiety. These psychometric measures have provided more relevant results than the physiological measures in the drug studies carried out so far. As a result, this review will focus only on the former.

The sequence of the experimental session is summarized in Table 2. After $15 \mathrm{~min}$ in the laboratory, initial measures are taken (B). Soon after, the subject swallows the

Table 2. Flowchart of the experimental session in the simulated public speaking (SPS) test as in Zuardi et al. (31).

\begin{tabular}{lll}
\hline Time (h:min) & Phases & Measures \\
\hline$-0: 25$ & Adaptation & \\
$-0: 10$ & Initial (B) & VAMS, STAI-T, STAI-S, SSS, BP, HR \\
$0: 00$ & Drug intake & \\
$1: 00$ & Pre-stress (P) & VAMS, STAI-S, SSS, BP, HR \\
$1: 10$ & Instructions & \\
$1: 13$ & Speech preparation & \\
$1: 15$ & Anticipatory anxiety (A) & VAMS, STAI-S, SSS, BP, HR \\
$1: 20$ & Onset of speech & \\
$1: 22$ & Performance anxiety (S) & VAMS, STAI-S, SSS, BP, HR \\
$1: 28$ & Resumes speech & \\
$1: 30$ & End of speech & \\
$2: 00$ & Final (F) & VAMS, STAI-T, STAI-S, SSS, BP, HR \\
\hline
\end{tabular}

VAMS, Visual Analog Mood Scale; STAI, State (S)-Trait (T) Anxiety Inventory; SSS, Somatic Symptoms Scale; BP, arterial blood pressure; HR, heart rate. 
capsule containing drug or placebo. Following a time interval needed to reach maximum plasma drug concentration, pre-stress $(\mathrm{P})$ measures are taken and pre-recorded instructions are played on a video screen. It is explained that the subject has 2 min to prepare a 4-min speech, and that this speech will be recorded on videotape for later analysis by a psychologist. In some of the reported studies the topic was emotionally neutral (e.g., physiological topics for medical students), while in others the subject was requested to talk about particularly anxietyprovoking life events. Anticipatory anxiety measures (A) are taken before speech onset. The address is interrupted after $2 \mathrm{~min}$ for taking measures of performance anxiety (S). Speech is resumed soon after and continued for another $2 \mathrm{~min}$. Post-stress measures (F) are taken 15 min later.

\begin{tabular}{|c|c|c|c|c|c|}
\hline \multirow[t]{2}{*}{ Drug } & \multirow{2}{*}{$\begin{array}{c}\text { Dose } \\
(\mathrm{mg}, \mathrm{po})\end{array}$} & \multicolumn{3}{|c|}{ Test phase } & \multirow[t]{2}{*}{ Reference } \\
\hline & & Before & During & After & \\
\hline \multirow[t]{5}{*}{ Diazepam } & 5 & 0 & 0 & 0 & McNair et al. (22) \\
\hline & 10 & - & - & - & \\
\hline & 10 & 0 & 0 & 0 & Graeff et al. (33) ${ }^{\mathrm{a}}$ \\
\hline & 10 & - & - & - & Guimarães et al. (34)a \\
\hline & 10 & - & 0 & - & Zuardi et al. (31) \\
\hline Lorazepam & 2 & - & - & 0 & Guimarães et al. (28) \\
\hline Flumazenil & $1^{\mathrm{b}}$ & 0 & - & 0 & Kapczinski et al. (35) \\
\hline Metergoline & 12 & $+^{\mathrm{C}}$ & 0 & 0 & Graeff et al. (33) ${ }^{\mathrm{a}}$ \\
\hline Buspirone & 5 & 0 & 0 & 0 & Guimarães et al. (34)a \\
\hline Ipsapirone & 5 & 0 & - & 0 & Zuardi et al. (31) \\
\hline Clomipramine & 25 & 0 & + & 0 & Guimarães et al. (28) \\
\hline \multirow[t]{2}{*}{ Ritanserin } & 2.5 & 0 & 0 & 0 & Guimarães et al. (36) \\
\hline & 10 & 0 & 0 & + & \\
\hline \multirow[t]{2}{*}{ Nefazodone } & 100 & 0 & 0 & 0 & Silva et al. (18) \\
\hline & 200 & 0 & + & 0 & \\
\hline \multirow[t]{2}{*}{ d-Fenfluramine } & 15 & 0 & 0 & - & Hetem et al. (12) \\
\hline & 30 & 0 & - & 0 & \\
\hline \multirow[t]{2}{*}{ - Tryptophan } & - & 0 & $+{ }^{d}$ & 0 & Monteiro-dos-Santos et al. (37) \\
\hline & - & 0 & 0 & $0^{e}$ & Shansis et al. (38) \\
\hline $\mathrm{mCPP}$ & 15 & 0 & 0 & 0 & Connel et al. (13) \\
\hline Maprotiline & 50 & - & - & - & Guimarães et al. (28) \\
\hline Cannabidiol & 300 & 0 & 0 & - & Zuardi et al. (31) \\
\hline
\end{tabular}

$\mathrm{mCPP}=$ methyl-chlorophenylpiperazine. + , increase; - , decrease; 0 , no change . aaudiocassette recorder; ${ }^{b}{ }_{i v}$; 'Spielberger's anxiety scale; $d_{i n}$ female, but not in male

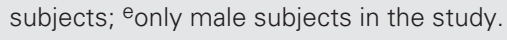

Table 3 summarizes the effect of drugs on anxiety measures before $(\mathrm{P})$ during $(\mathrm{A}$ and/or S) and after (F) stress (12,13,18,22,28, 31,33-38). It can be seen that the benzodiazepine anxiolytics diazepam and lorazepam consistently decreased anxiety at pre-stress (P). The only exception is the study by Graeff and co-workers (33), which used an audiocassette instead of video recording, and the STAI-S scale, which is less sensitive than VAMS in detecting drug effects $(38,39)$. The level of anxiety during stress may be equal to or lower than in placebo control (Table 3), but in every case the increase in anxiety induced by SPS (phase A or S minus phase P) was not significantly modified by the benzodiazepines (data not shown in Table 3 ). The noradrenaline reuptake inhibitor maprotiline had a similar effect. In contrast, drugs that primarily affect serotonergic neurotransmission, except for metergoline, do not change pre-stress anxiety. When effective, they either increase or decrease stressinduced anxiety. The difference in drug response between basal anxiety and SPS-induced anxiety indicates that two types of emotional states are generated by each condition. The former seems to be akin to the conditioned anxiety generated by aversive conditioning (see above), whereas the SPSinduced anxiety is a distinct type of emotion, resistant to anxiolytics.

Several drug assays have been carried out to test the dual 5-HT-anxiety hypothesis (14). This hypothesis predicts that drugs that enhance the action of 5-HT may decrease SPS-induced anxiety, while drugs that reduce the action of 5-HT may have the opposite effect. In this way, the pro-anxiety effect of the 5- $\mathrm{HT}_{2 \mathrm{~A} / 2 \mathrm{C}}$-receptor blocker ritanserin is consistent with this prediction. Also, the anxiogenic effect observed with either clomipramine or nefazodone (Figure 4) would be an expected result if 5-HT reuptake inhibitors acted mainly by enhancing the action of 5-HT on autosomic 5- $\mathrm{HT}_{1 \mathrm{~A}}$ receptors, as discussed above. 
However, the absence of a similar effect of buspirone and, even more disturbing, the anxiolytic effect of the similar $5-\mathrm{HT}_{1 \mathrm{~A}}$ agonist ipsapirone do not support the hypothesis being tested. Also, tryptophan depletion, obtained by dietary restriction plus intake of a concentrated amino acid drink devoid of tryptophan, had no effect on SPS-induced anxiety $(37,38)$. Nevertheless, in the former study there was an increase in performance anxiety measured by STAI in female, though not in male subjects (37). The last result is consistent with the dual 5-HT-anxiety hypothesis (14).

In the opposite direction, the 5-HT-releasing agent d-fenfluramine, supposedly increasing 5-HT at postsynaptic receptors, decreased SPS-induced anxiety (Figure 3 ). The last result is that predicted by the dual 5-HTanxiety hypothesis.

The SPS test was used in the above comparative study between panic patients and controls, in addition to aversive conditioning (20). The rationale that guided this research was the hypothesis that brain structures responsible for defensive reactions to proximal threat represent the main neural substrate of panic disorder (5,14,39-41). Admitting that SPS measures a species-specific response, panic patients should be different from controls in this model. Indeed, panic patients showed higher baseline levels of VAMS-measured anxiety than controls and, unlike controls, their anxiety failed to increase before and during speech. These results indicate that panic patients process the type of anxiety generated by the SPS test in an abnormal manner (20). Another recent study made use of the SPS test to investigate the response to stress of autistic-like children. The results obtained showed that these children reacted far less than controls to the SPS, as indicated by heart rate and salivary cortisol measures (42). The authors suggested that the impaired responses to psychosocial stress could be the result of limited ability to react adequately to the social environment.
The same impairment in stress processing has been found in schizophrenia, and might be a factor in the vulnerability of autistic-like children to developing schizophrenia.

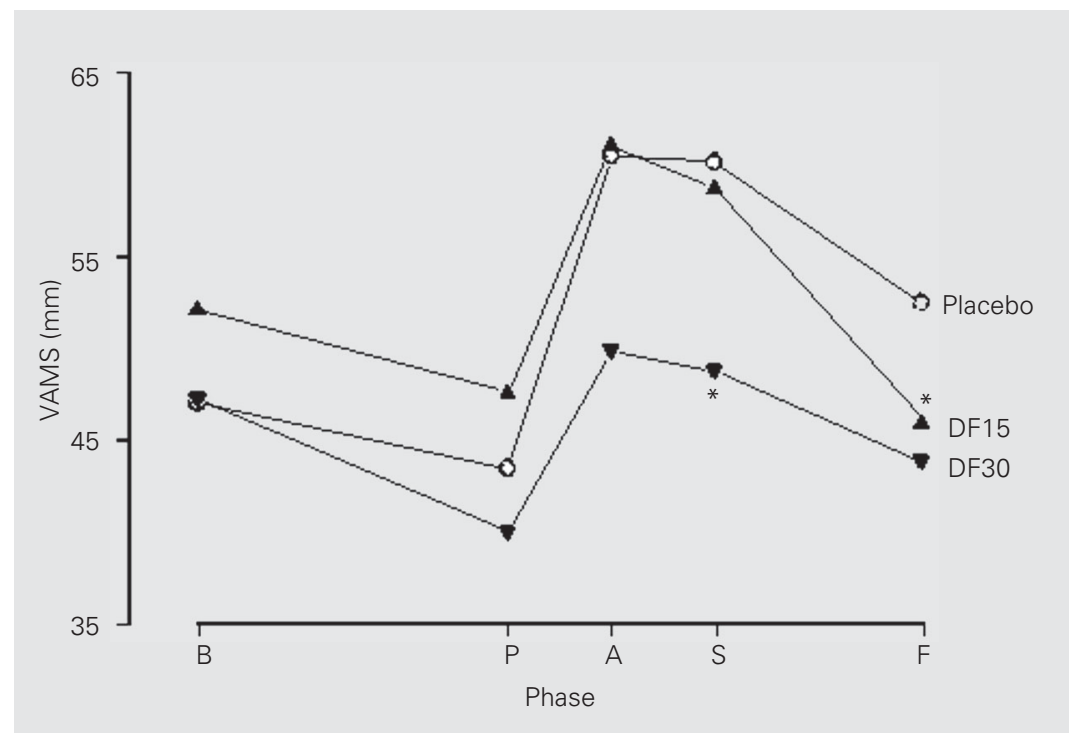

Figure 3. d-Fenfluramine reduces the anxiety induced by simulated public speaking in healthy volunteers. Points indicate mean of 15 subjects in $\mathrm{mm}$ of the Visual Analog Mood Scale (VAMS). B: initial measurement, $P$ : pre-stress, $A$ : anticipatory anxiety, $S$ : speaking performance anxiety, F: final, post-stress measure. DF15: $15 \mathrm{mg}$, DF30: $30 \mathrm{mg}$ d-fenfluramine. ${ }^{*} \mathrm{P}<0.05$ compared to placebo (Duncan test). Modified from Ref. 12.

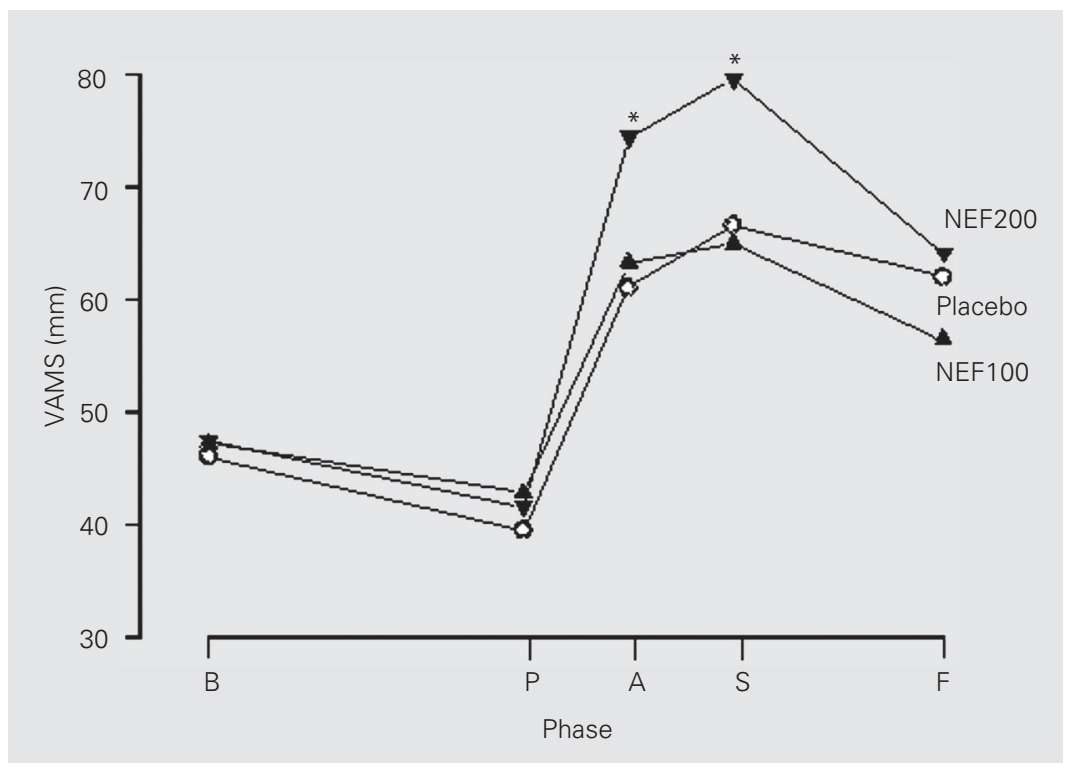

Figure 4. Nefazodone enhances the anxiety induced by simulated public speaking. $\mathrm{N}=15$. NEF100: $100 \mathrm{mg}$, NEF200: $200 \mathrm{mg}$ nefazodone. Other specifications are given in the legend to Figure 3. Modified from Ref. 18. 


\section{Stroop Color-Word test}

The SCWT was originally developed to investigate basic cognitive functions. In 1935, Stroop observed that naming the color of words appearing in another color takes more time than naming the color of a word appearing in the same color. These phenomena became known as Stroop's interference and congruence effects, respectively. Therefore, the SCWT produces a cognitive conflict that may induce anxiety $(43,44)$.

Nakano and co-workers (45) were the first to standardize the instrument, and their method is described next. There are 3 black cards with elements arranged in a $10 \times 10$ matrix. The first card, named the word card, has words written in white naming five colors: red, blue, green, yellow and purple. The second, the color card, contains only colored circles $8 \mathrm{~mm}$ in diameter. In the third, the color-word card, colors and words are discordant; for instance, the word red is printed in green. For the test, the subject is required to read aloud the word card, to name the colors on the color card and to name the colors on the color-word card as fast as possible. The experimenter points out each error - reading the word instead of naming the color - to the subject and records the frequency of errors as well as the time taken to perform the test. It is assumed that psychological stress induces errors and slows the test performance. In the study by Nakano and co-workers (45) volunteers were selected on the basis of trait anxiety. In subjects with

Table 4. Effects of drugs on state anxiety in the Stroop Color-Word test.

\begin{tabular}{lccl}
\hline Drug & Dose $(\mathrm{mg}, \mathrm{po})$ & Effect & Reference \\
\hline Diazepam & 5 & - & Nakano et al. (45) \\
& 5 & - & Leite et al. (46) \\
Lorazepam & $0.94^{\mathrm{a}}$ & 0 & Tulen et al. (47) \\
Nabilone & 2 & - & Nakano et al. (45)
\end{tabular}

-, decrease (anxiolytic); 0, no change.

${ }^{a}$ cumulative dose after repeated drug administration and testing. high trait anxiety, state anxiety induced by the SCWT was alleviated by diazepam and, to a lesser extent, by nabilone. The latter drug is a synthetic cannabinoid receptor ligand and potential anxiolytic agent (Table 4 ; 45-47). Tulen and co-workers (47) modified the former procedure using a videotaperecorded presentation in which the words red, green, blue and yellow appear on a TV screen colored in one of these colors, either congruently or incongruently, in a random sequence. The subject is required to write the colors of the words on a sheet of paper as they appear on the TV screen. The results obtained showed that this procedure induces feelings of anxiety and also increases plasma and urinary adrenaline, heart rate, respiration rate, electrodermal activity, and electromyography, and decreases finger pulse amplitude. In a further study the subjects repeatedly performed a 10-min version of the SCWT, with 10 min of rest between tests (46). Lorazepam was administered before each rest period in increasing doses of 0.0 , $0.6,0.13,0.25$ and $0.5 \mathrm{mg}$ (total cumulative dose: $0.94 \mathrm{mg}$ ). Heart rate showed a dosedependent decrease during rest with an ED50 of $0.13 \mathrm{mg}$ lorazepam, while the drug had no effect on the cardiovascular and plasma catecholamine responses to the SCWT. Subjective fatigue and reaction time increased significantly after $0.94 \mathrm{mg}$ lorazepam, while vigor decreased at the same dose. However, the drug did not affect state anxiety measured soon after the SCWT (Table 4). These data show differential effects of lorazepam on cardiovascular, biochemical and psychological function. While heart rate was suppressed at low doses during rest and reaction time and subjective fatigue increased at doses that induced sedation, state anxiety and physiological response patterns to the SCWT were not influenced by lorazepam.

Leite and co-workers (46) recorded the performance of the SCWT on videotape, with the subject being able to see him/herself performing the test on a TV screen. This 
procedure increased state anxiety in volunteers with normal levels of trait anxiety (between 30 and 50 on STAI-T), and this increase was attenuated by diazepam (Table 4). In contrast, the standard, non-recorded procedure increased state anxiety only in volunteers with high trait anxiety (above 50 on STAI-T). The need to select volunteers with high trait anxiety to obtain measurable increases in state anxiety has also been stressed by Palma and co-workers (27). The results of a further study by Silva and Leite (11) have shown that the video-recorded SCWT procedure induces physiological, in addition to psychological, changes, which may be useful to measure drug effects more objectively.

Overall, the pharmacological results obtained so far with the SCWT are few, and one study with lorazepam yielded negative results (Table 4). The video recording of the SCWT developed by Leite and co-workers (46) combines the SCWT with an element of the SPS test. Further drug studies are needed to determine the type of anxiety generated by such mixed procedure.

\section{Fear-potentiated startle}

The jump response of rats to a loud noise increases in the presence of an aversive conditioned stimulus, that is, a previously neutral stimulus that has been paired with an electric foot shock or another primarily aversive stimulus (48). Davis (49) extensively studied this phenomenon, which has been named fear-potentiated startle (FPS). Neurophysiological results obtained in his laboratory indicate that the conditioned stimulus activates the central nucleus of the amygdala through a pathway involving the lateral geniculate nucleus, perirhinal cortex, and lateral and basolateral amygdaloid nuclei. The central nucleus of the amygdala then projects directly to the acoustic startle pathway so as to modulate the startle response. Furthermore, reported pharmacological results qualify this test as an animal model predictive of generalized anxiety disorder (1).

Grillon and co-workers (50) developed a similar model for human subjects. They recorded the eye blink reflex elicited by a loud white noise (106 dB, $40 \mathrm{~ms})$. The protocol described in a later study (51) is as follows. The subject sits on a comfortable chair looking at a front panel provided with a digital timer and two lights, one red and the other green. Electric shocks are delivered through electrodes attached to on one of the wrists. Shocks may occur when the red light is on (threat condition), but never when the green light is on (safe condition). The experimental session is divided into three phases: habituation, threat and recovery. The eye blink reflex is recorded in three trials, separated by 4-min inter-trial intervals. Each trial starts with 6 presentations of the noise alone. Then, the same noise is presented alternatively 6 times under the threat condition and 6 times under the safe condition. The subject is informed that he/she may receive 1 to 3 shocks during the session, of increasing intensity. Actually, only one shock $(1.5 \mathrm{~mA}, 50 \mathrm{~s})$ is delivered during the final $5 \mathrm{~s}$ of the last threat condition in trial 2 . The subject monitors the duration of each condition by watching the timer, and is informed that the shocks may occur only in the last $10 \mathrm{~s}$ of the threat condition. The threat condition lasts $50 \mathrm{~s}$, while the safe condition lasts $60 \mathrm{~s}$.

In contrast to the animal model, few drug studies have been performed so far with the human version of the FPS. Their results are summarized in Table 5 (52-55).

\begin{tabular}{lccl}
\multicolumn{2}{l}{ Table 5. Effects of drugs on fear-potentiated startle. } \\
\hline Drug & Dose (mg, po) & Effect & Reference \\
\hline Diazepam & 10 & - & Patrick et al. (52) \\
& 15 & - & \\
Alprazolam & 10 & - & Bitsios et al. (53) \\
Ethanol & $0.25-1$ & - & Riba et al. (54) \\
& Drink & 0 & Curtin et al. (55) \\
\hline
\end{tabular}

-, decrease (anxiolytic); 0, no change. 
It may be seen that the two benzodiazepine anxiolytics diazepam and alprazolam consistently attenuated the enhancement of startle caused by the threat condition. Nevertheless, there is a negative result with ethanol. Although more pharmacological investigations are necessary to validate the test, these results are consistent with the animal data $(1,49)$, supporting FPS as a fair candidate to an experimental anxiety test. The face validity of the procedure is also clear and, together with the observed sensitivity to anxiolytics, strongly suggests that the test provokes conditioned, anticipatory anxiety, seemingly related to generalized anxiety disorder (14). Accordingly, Grillon and coworkers (51) have shown that FPS differed in the low and high anxiety subjects. Startle potentiation was larger in the high anxiety group as compared to the low anxiety group, as assessed with the STAI-S (see above). The time course of startle modulation suggested a longer duration of anticipatory anxiety in the high anxiety group. Trait anxiety, assessed with the STAI-T, was not related to individual differences in either baseline or FPS.

As observed for psychopathology, an increase in FPS compared to normal controls has been reported in panic disorder, though only in patients less than 40 years old (56). Increased FPS was also found in post-traumatic stress disorder (57) and in the adoles- cent offspring of parents with anxiety disorders (58). The last result suggests that FPS may detect vulnerability to anxiety disorders.

\section{Conclusion}

From the reviewed evidence, it may be concluded that aversive conditioning to tones and FPS are based on classical conditioning of anticipatory anxiety. Accordingly, their sensitivity to benzodiazepines suggests that they are related to generalized anxiety disorder. On the other hand, the increase in anxiety determined by simulated public speaking is resistant to these drugs and sensitive to drugs affecting serotonergic neurotransmission. This pharmacological profile, together with reported epidemiological evidence, suggests that the emotional state generated by public speaking represents a species-specific response, which may be related to social phobia and panic disorder. The status of the SCWT remains uncertain.

A comprehensive review of animal models of anxiety led to the conclusion that tests with approach-avoidance conflict are the best predictors of drug effects on generalized anxiety disorder (1). Although it may be said that the SCWT generates a cognitive conflict between the color and meaning of the incongruent word, so far no human model with approach-avoidance conflict has been developed.

\section{References}

1. Graeff FG \& Zangrossi Jr H (2002). Animal models of anxiety disorders. In: D'haenen $H$, den Boer JA, Westenberg $H$ \& Willner $P$ (Editors), Textbook of Biological Psychiatry. John Wiley \& Sons, London, UK, 879-893.

2. Janke W \& Netter $P$ (1983). Anxiolytic effects of drugs: approaches, methods and problems. Neuropsychobiology, 9: 33-40.

3. Gray JA \& McNaughton N (2000). The Neuropsychology of Anxiety. Oxford University Press, Oxford, UK.

4. Bond AJ, James DC \& Lader MH (1974). Physiological and psychological measures in anxious patients. Psychological Medicine, 4: 364-373.

5. Fowles DC (2000). Electrodermal hyporeactivity and antisocial be- havior: does anxiety mediate the relationship? Journal of Affective Disorders, 61: 177-189

6. Vila J \& Beech HR (1977). Vulnerability and conditioning in relation to the human menstrual cycle. British Journal of Social and Clinical Psychology, 16: 69-75.

7. Wang M (1986). Changes in psychophysiological and conditioning variables during chlomethiazole-medicated and unmedicated ethanol withdrawal: preliminary report. Acta Psychiatrica Scandinavica, 73 (Suppl 329): 146-152.

8. Guimarães FS, Hellewell J, Hensman R, Wang M \& Deakin JFW (1991). Characterization of a psychophysiological model of classical fear conditioning in healthy volunteers: influence of gender, instruc- 
tions, personality and placebo. Psychopharmacology, 104: 231-236.

9. Hellewell JS, Guimarães FS, Wang M \& Deakin JF (1999). Comparison of buspirone with diazepam and fluvoxamine on aversive classical conditioning in humans. Journal of Psychopharmacology, 13: 122-127.

10. Hensman R, Guimarães FS, Wang M \& Deakin JFW (1991). The effects of ritanserin on aversive classical conditioning in humans. Psychopharmacology, 104: 220-224.

11. Silva FT \& Leite JR (2000). Physiological modifications and increase in state anxiety in volunteers submitted to the Stroop Color-Word Interference Test: A preliminary study. Physiology and Behavior, 70: 113-118.

12. Hetem LA, de Souza CJ, Guimarães FS, Zuardi AW \& Graeff FG (1996). Effect of d-fenfluramine on human experimental anxiety. Psychopharmacology, 127: 276-282.

13. Connel J, Hellewell JSE \& Deakin JFW (1994). Effects of a 5HT2C agonist in two models of anxiety in volunteers. Journal of Psychopharmacology, 8: A23 (Abstract).

14. Deakin JFW \& Graeff FG (1991). 5-HT and mechanisms of defence. Journal of Psychopharmacology, 5: 305-315.

15. Bel N \& Artigas F (1992). Fluvoxamine preferentially increases extracellular 5-hydroxytryptamine in the raphe nuclei: an in vivo microdialysis study. European Journal of Pharmacology, 229: 101-103.

16. Mongeau R, Blier P \& de Montigny C (1997). The serotonergic and noradrenergic systems of the hippocampus: their interactions and the effects of antidepressant treatments. Brain Research Bulletin, 23: 145-195.

17. Taylor DP, Carter RB, Eison AS, Mullins UL, Smith HL, Torrente JR, Wright RN \& Yocca FD (1995). Pharmacology and neurochemistry of nefazodone, a novel antidepressant drug. Journal of Clinical Psychiatry, 56 (Suppl 6): 3-11.

18. Silva M, Hetem LA, Guimarães FS \& Graeff FG (2001). Opposed effects of nefazodone in two human models of anxiety. Psychopharmacology, 156: 454-460.

19. Ashcroft KR, Guimarães FS, Wang M \& Deakin JF (1991). Evaluation of a psychophysiological model of classical fear conditioning in anxious patients. Psychopharmacology, 104: 215-219.

20. Del-Ben CM, Vilela JAA, Hetem LAB, Guimarães FS, Graeff FG \& Zuardi AW (2001). Do panic patients process unconditioned fear vs. conditioned anxiety differently than normal subjects? Psychiatry Research, 104: 227-237.

21. Geer JH (1965). The development of a scale to measure fear. Behaviour Research and Therapy, 3: 45-53.

22. McNair DM, Frankenthaler LM, Czerlinsky T, White TW, Sasson S \& Fisher S (1982). Simulated public speaking as a model of clinical anxiety. Psychopharmacology, 77: 7-10.

23. Phillips GC, Jones GE, Rieger ER \& Snell JB (1997). Normative data for the personal report of confidence as a speaker. Journal of Anxiety Disorders, 11: 215-220.

24. Brunello N, den Boer JA, Judd LL et al. (2000). Social phobia: diagnosis and epidemiology, neurobiology and pharmacology, comorbidity and treatment. Journal of Affective Disorders, 60: 61-74.

25. Furmark T, Tillfors M, Everz P, Marteinsdottir I, Gefvert O \& Fredrikson M (1999). Social phobia in the general population: prevalence and sociodemographic profile. Social Psychiatry and Psychiatric Epidemiology, 34: 416-424.

26. Stein MB, Walker JR \& Forde DR (1996). Public-speaking fears in a community sample. Prevalence, impact on functioning, and diagnostic classification. Archives of General Psychiatry, 53: 169-174.

27. Palma SM, Guimarães FS \& Zuardi AW (1994). Anxiety induced by simulated public speaking and stroop colour word test in healthy subjects: effects of different trait-anxiety levels. Brazilian Journal of Medical and Biological Research, 27: 2895-2902.

28. Guimarães FS, Zuardi AW \& Graeff FG (1987). Effect of chlorimipramine and maprotiline on experimental anxiety in humans. Journal of Psychopharmacology, 1: 184-192.

29. Spielberger CD, Gorsuch RI \& Lushene RE (1970). Manual for the State-Trait Anxiety Inventory. Consulting Psychologists Press, Palo Alto, CA, USA.

30. Norris $H$ (1971). The action of sedatives on brainstem oculomotor systems in man. Neuropharmacology, 10: 181-191.

31. Zuardi AW, Cosme RA, Graeff FG \& Guimarães FS (1993). Effects of ipsapirone and cannabidiol on human experimental anxiety. Journal of Psychopharmacology, 7: 82-88.

32. Guimarães FS, Zuardi AW, Gentil Filho V \& Graeff FG (1988). A importância do treinamento prévio para uma melhor utilização da escala analógica de humor de Norris. Revista da Associação Brasileira de Psiquiatria, 10: 5-7.

33. Graeff FG, Zuardi AW, Giglio JS, Lima Filho EC \& Karniol IG (1985). Effect of metergoline on human anxiety. Psychopharmacology, 86: 334-338.

34. Guimarães FS, Kohem CL, Fillmann HS, de Vecino MCA, de Paoli CL, Ribeiro AMS, Teixeira CC \& Wannmacher L (1989). A simple simulated public speaking test for evaluating anxiolytic drugs. Brazilian Journal of Medical and Biological Research, 22: 1083-1089.

35. Kapczinski F, Curran HV, Gray J \& Lader M (1994). Flumazenil has an anxiolytic effect in simulated stress. Psychopharmacology, 114: 187189.

36. Guimarães FS, Mbaya OS \& Deakin JFW (1997). Ritanserin facilitates anxiety in a simulated public-speaking paradigm. Journal of Psychopharmacology, 11: 225-231.

37. Monteiro-dos-Santos PC, Graeff FG, dos-Santos JE, Ribeiro RP, Guimarães FS \& Zuardi AW (2000). Effects of tryptophan depletion on anxiety induced by simulated public speaking. Brazilian Journal of Medical and Biological Research, 33: 581-587.

38. Shansis FM, Busnello JV, Quevedo J, Forster L, Young S, Izquierdo I \& Kapczinski $F$ (2000). Behavioural effects of acute tryptophan depletion in healthy male volunteers. Journal of Psychopharmacology, 14: 157-163.

39. Gentil V (1988). The aversive system, 5HT and panic attacks. In: Simon P, Soubrié P \& Willocher D (Editors), Animal Models of Psychiatric Disorders. Vol. 1. Karger, Basel, Switzerland, 142-145.

40. Graeff FG (1988). Animal model of aversion. In: Simon P, Soubrié P \& Willocher D (Editors), Animal Models of Psychiatric Disorders. Vol. 1. Karger, Basel, Switzerland, 115-141.

41. Graeff FG (1991). Neurotransmitters in the dorsal periaqueductal gray and animal models of panic anxiety. In: Briley M \& File SE (Editors), New Concepts in Anxiety. Macmillan Press, London, UK, 288-312.

42. Jansen LM, Gispen-de Wied CC, Van der Gaag RJ, ten Hove F, Willemsen-Swinkels SW, Harteveld E \& Van Engeland H (2000). Unresponsiveness to psychosocial stress in a subgroup of autisticlike children, multiple complex developmental disorder. Psychoneuroendocrinology, 25: 753-764.

43. Tulen JH, Moleman P, van Steenis HG \& Boomsma F (1989). Characterization of stress reactions to the Stroop Color Word Test. Pharmacology, Biochemistry and Behavior, 32: 9-15.

44. Jensen AR \& Rohwer Jr WD (1966). The Stroop color-word test: a review. Acta Psychologica, 25: 36-93.

45. Nakano S, Gillespie HK \& Hollister LE (1978). A model for evaluation of antianxiety drugs with the use of experimentally induced stress: Comparison of nabilone and diazepam. Clinical Pharmacology and 
Therapeutics, 23: 54-62.

46. Leite JR, Seabra M de L, Sartori VA \& Andreatini R (1999). The videorecorded Stroop Color-Word Test as a new model of experimentallyinduced anxiety. Progress in Neuro-psychopharmacology and Biological Psychiatry, 23: 809-822.

47. Tulen JH, Moleman P, Boomsma F, van Steenis HG \& van den Heuij VJ (1991). Dose-dependent effects of intravenous lorazepam on cardiovascular activity, plasma catecholamines and psychological function during rest and mental stress. Psychopharmacology, 105: 77-83.

48. Brown JS, Kalish HI \& Farber IE (1951). Conditioned fear as revealed by the magnitude of startle response to an auditory stimulus. Journal of Experimental Psychology, 41: 317-327.

49. Davis M (1993). Pharmacological analysis of fear-potentiated startle. Brazilian Journal of Medical and Biological Research, 26: 235-260.

50. Grillon C, Ameli R, Woods SW, Merikangas K \& Davis M (1991). Fear-potentiated startle in humans: effects of anticipatory anxiety on the acoustic blink reflex. Psychophysiology, 28: 588-595.

51. Grillon C, Ameli R, Foot M \& Davis M (1993). Fear-potentiated startle: relationship to the level of state/trait anxiety in healthy subjects. Biological Psychiatry, 33: 566-574.

52. Patrick CJ, Berthot BD \& Moore JD (1996). Diazepam blocks fearpotentiated startle in humans. Journal of Abnormal Psychology, 105:
89-96.

53. Bitsios P, Philpott A, Langley RW, Bradshaw CM \& Szabadi E (1999). Comparison of the effects of diazepam on the fear-potentiated startle reflex and the fear-inhibited light reflex in man. Journal of Psychopharmacology, 13: 226-234.

54. Riba J, Rodriguez-Fornells A, Urbano G, Morte A, Antonijoan R \& Barbanoj MJ (2001). Differential effects of alprazolam on the baseline and fear-potentiated startle reflex in humans: a dose-response study. Psychopharmacology, 157: 358-367.

55. Curtin JJ, Lang AR, Patrick CJ \& Stritzke WG (1998). Alcohol and fear-potentiated startle: the role of competing cognitive demands in the stress-reducing effects of intoxication. Journal of Abnormal Psychology, 107: 547-557.

56. Grillon C, Ameli R, Goddard A, Woods SW \& Davis M (1994). Baseline and fear-potentiated startle in panic disorder patients. Biological Psychiatry, 35: 431-439.

57. Morgan 3rd CA, Grillon C, Southwick SM, Davis M \& Charney DS (1995). Fear-potentiated startle in posttraumatic stress disorder. Biological Psychiatry, 38: 378-385.

58. Grillon C, Dierker L \& Merikangas KR (1998). Fear-potentiated startle in adolescent offspring of parents with anxiety disorders. Biological Psychiatry, 44: 990-997. 